\title{
Na história do ensino da literatura no Brasil: problemas e possibilidades para o século XXI
}

\section{In the history of literature teaching in Brazil: problems and possibilities for the $21^{\text {st }}$ century}

\author{
Maria do Rosário Longo Mortatti ${ }^{1}$
}

\begin{abstract}
RESUMO
Serão problematizadas as relações entre literatura e ensino, com ênfase na história recente do ensino da literatura (infantil) na educação escolar brasileira. O objetivo é discutir a importância da leitura (literária) da configuração de textos literários para o processo de formação de leitores, assim como as implicações para a formação de professores para a educação infantil e anos iniciais do ensino fundamental.

Palavras-chave: ensino da literatura; história do ensino da literatura; literatura infantil e juvenil; leitura; configuração textual.
\end{abstract}

\begin{abstract}
The relations between literature and education will be approached, with emphasis on the recent history of (children's) literature teaching in the Brazilian school education. The aim is to discuss the importance of (literary) reading on literary texts configurations in the process of readers' formation, as well as the implications for teachers' training for early childhood and elementary education.
\end{abstract}

Keywords: literature teaching; history of literature teaching; children's and youth literature; reading; textual configuration.

DOI: $10.1590 / 0104-4060.36317$

1 Universidade Estadual Paulista - Campus de Marília, Programa de Pós-Graduação em Educação. Avenida Hygino Muzzi Filho, nº 737, Marília, São Paulo, Brasil. CEP: 17525-900. 


\section{Introdução}

Ao iniciar a elaboração deste artigo, vieram-me à mente questões sobre as relações entre literatura, educação e ensino, das quais venho me ocupando desde a década de 1980, no exercício de minhas atividades como professora e pesquisadora. Por isso, pareceu-me que tudo o que poderia escrever sobre o assunto já está, de certo modo, registrado em textos meus e de outros pesquisadores de minha geração acadêmica e intelectual.

Aos questionamentos iniciais, porém, sobrepuseram-se tanto a necessidade de dialogar com as urgências deste momento histórico quanto a compreensão da pertinência e atualidade do assunto. Abordá-los neste texto, portanto, pode representar a possibilidade de não somente reafirmar reflexões e pontos de vista, mas também de compor - ao estilo de Pierre Menard -, por meio de nova configuração textual, uma síntese do que venho elaborando há três décadas.

O objetivo é o de ao menos apresentar às novas gerações de professores $\mathrm{e}$ pesquisadores um ponto de vista sobre as relações (desejadas) entre literatura, educação e ensino, no século XXI, e suas implicações para a formação de professores para a educação infantil e anos iniciais do ensino fundamental. Essas são as possíveis contribuições deste artigo.

\section{Ensino da literatura e literatura infantil e juvenil: tradição fundada na década de 1980}

Com o fim da ditadura política que sucedeu o golpe militar de 1964, a partir da década de 1980 se intensificaram a denúncia da "crise da educação" e os debates sistemáticos sobre a persistência do "ensino tradicional". No contexto de reorganização política e social do Brasil, esse debate envolveu diferentes sujeitos e segmentos representativos da sociedade civil brasileira, especialmente professores do ensino de $1^{\circ}$ e $2^{\circ}$ Graus e do ensino superior e entidades que os representavam. Visando à construção da educação democrática para uma sociedade democrática, foram-se formulando e implementando programas governamentais, como aqueles destinados à superação da "crise da educação" e as correlatas "crise da alfabetização" e "crise da leitura" no Brasil. Foi-se intensificando, então, o interesse pelo estudo e pela pesquisa, em programas de pós-graduação de educação, sobre esses e outros problemas educacionais. 
Também as relações entre educação e literatura se tornaram temas de discussão e objetos de pesquisa e estudos sistemáticos produzidos por pesquisadores da área dos estudos literários no diálogo crítico com as ciências da educação.

Os resultados foram configurando novos modos de pensar, sentir, querer e agir, derivados de questionamentos contundentes, por exemplo, dos antigos modelos escolares: de ensino de história literária, por meio das escolas literárias, autores e obras canônicos no ensino de $2^{\circ} \mathrm{Grau}$; ou de utilização escolar do texto literário como pretexto para ensinar gramática normativa da língua, valores morais e cívico-patrióticos, ou para formar o "aluno crítico" da ideologia dominante. Visando à formação de cidadãos críticos e ativos, como agentes do projeto desejado de transformação social, denunciavam-se os "usos e abusos da literatura na escola", o "ensino pela literatura", o "texto como pretexto" (LAJOLO, 1979; 1982). E se propunham novos lugar e função para o texto literário na educação escolar, buscando enfrentar coerentemente a paradoxal e conflituosa relação entre a liberdade criadora da literatura (também a infantil e juvenil) e a disciplinarização de seu ensino e da leitura imposta pela escola (LEITE, 1983; ZILBERMAN, 1982; MAGNANI, 1989²).

Imersa no clima acadêmico-intelectual da época, na condição de professora de língua e literatura no ensino do $1^{\circ}$ e $2^{\circ}$ graus e de aluna do mestrado em Educação na FE/UNICAMP, elaborei as primeiras reflexões sobre a relação entre literatura e educação. Fundamentada em textos de Theodor Adorno, Roman Jakobson, Leôncio Basbaum e Maria Luísa Santos Ribeiro, enfoquei a literatura infantil, por meio da análise do livro Criança, meu amor, de Cecília Meireles, com o objetivo de:

Estudar o passado para melhor compreender o presente [...] Tentaremos ver o conceito de literatura que [Cecília Meireles] nos oferece e que função tem essa literatura destinada ao pequeno público escolar. E dentro desses pressupostos procuraremos mostrar como a autora consegue superar a dicotomia educação pela literatura x educação para a literatura citada por Marisa Lajolo em Usos e Abusos da Literatura na Escola (mimeog.). Tentaremos ver isso através de uma análise conjunta dos textos como estrutura e do contexto em que se insere, da realidade de que parte e a quem se destina.(MAGNANI, 1980, fl.2, grifos da autora).

2 Trata-se do livro resultante da dissertação de mestrado da autora, defendida em 1986, junto ao Programa de Pós-Graduação em Educação (PPGE) da Faculdade de Educação da UNICAMP (FE/UNICAMP). 
Naquele momento histórico, as discussões se referiam: à disciplina Literatura (Brasileira e/ou Portuguesa), que constava do currículo do ensino de $2^{\circ}$ Grau; ou à matéria "literatura", que integrava a disciplina Língua Portuguesa do currículo de $5^{\mathrm{a}}$ a $8^{\mathrm{a}}$ séries do ensino de $1^{\circ} \mathrm{Grau}$. Nessa matéria se estudavam, por meio do livro didático, aspectos de análise literária e (fragmentos de) textos de autores consagrados da literatura brasileira ou se estudavam livros de coleções destinadas ao público juvenil, acompanhados de "fichas de leitura"; ou, ainda, à leitura da literatura infantil nas séries iniciais ( $1^{\mathrm{a}}$ a $4^{\mathrm{a}}$ séries $)$ do ensino de $1^{\circ}$ grau em cujo currículo, porém, não consta(-va) matéria com denominação equivalente ${ }^{3}$, mas se estudavam (também em livros didáticos) fragmentos de textos para crianças ou se liam livros de literatura infantil, acompanhados de "fichas de leitura".

Refletindo sobre a escolarização da leitura (literária), eu criticava o uso do livro didático nas aulas de Língua Portuguesa e os problemas que ele acarreta: "[...] certamente, não permite uma leitura crítica e transformadora da realidade, tornando paradoxal a intenção de [...] despertar o prazer de ler e escrever." (MAGNANI, 1988, p. 19-20). Criticava, ainda, o abandono do texto, como obra de linguagem, problema relacionado com as finalidades imediatistas e utilitárias que determinam modos e métodos de ensino da leitura da literatura na escola: "[...] ler para fazer exercícios de interpretação, para estudar itens de conteúdos, para adquirir modelos de escrita, para gostar e se habituar, para conscientizar e politizar..." (MAGNANI, 1988, p. 18).

Dada a urgência maior de enfrentamento dos problemas da escolarização inicial de crianças, questões relativas à leitura da literatura infantil e juvenil e sua utilização na escola passaram a demandar a atenção de pesquisadores.

A produção acadêmico-científica sobre o gênero começa a ganhar impulso a partir dos anos de 1980, com a expansão dos cursos de pós-graduação, iniciando-se o processo de consolidação como campo de conhecimento caracterizado, predominantemente, por dois tipos de abordagens, que passaram a se desenvolver: do ponto de vista dos estudos literários, enfatizando-se a necessidade de pressupostos e procedimentos de investigação buscados à história, teoria e crítica literárias - marcadas sobretudo pela tendência estruturalista e histórico-sociológica-, os quais propiciassem discussão da esteticidade dos textos do gênero como fator de superação das marcas pedagogizantes características desses textos e advindas de sua relação original com a educação e a escola; e do ponto de vista dos

3 Deve-se recordar que nesse nível de ensino não há registros, na história da educação brasileira, de disciplinas com denominação "literatura" ou "literatura infantil". 
estudos em educação, enfatizando-se, inicialmente, a necessidade de se denunciar a ideologia subjacente aos textos do gênero e, posteriormente, de se buscarem propostas didáticas para sua adequada seleção e utilização nas escolas, a fim de se formarem leitores críticos e transformadores da sociedade (MAGNANI, 2001, p. xiv-xv).

Ainda naquele momento histórico, os novos sujeitos, necessidades, finalidades, contextos, modos e interlocutores da produção de discursos sobre literatura infantil vieram-se opor, em diferentes medidas, ao discurso até então dominante, marcado pelo ponto de vista da psicologia (da educação). Esse discurso (ainda hoje presente) integrava a tradição fundada por Manoel Bergström Lourenço Filho, que afirmava: "Há uma 'literatura' específica para as crianças, justamente porque estas a consomem; porquanto se torna possível levar-lhes a emoção estética, através das letras, nas condições naturais de seu gradativo desenvolvimento mental, emocional e cultural.” (LOURENÇO FILHO, 1943, p. 157).

Segundo essa compreensão, enfatizava-se a necessidade de que "[...] aqueles que escrevem para crianças aceitem e estudem a 'estética evolutiva, ou genética', para garantir que a literatura infantil atinja seu fim: a arte a serviço da formação/educação das crianças e jovens. O limite da liberdade criadora é, portanto, o agradável a serviço do útil." (MORTATTI, 2008a, p. 7). ${ }^{4}$

Foi a essa tradição que se opuseram, em diferentes medidas e modos, as novas discussões que enfatizaram a esteticidade/literariedade necessária aos textos de literatura infantil e juvenil, como fator de superação das marcas moralizantes e pedagogizantes desse gênero literário, em decorrência de sua relação original com a educação e com a escola.

Especificamente em relação à história, teoria e crítica da literatura infantil, são textos fundadores dessa nova tradição os de Zilberman (1981); Zilberman e Magalhães (1982), Lajolo e Zilberman (1984); Coelho (1984), Rosemberg (1985); Perrotti (1986). Esses textos integram, juntamente com os de Lourenço Filho (1943), Meireles (1951), Azevedo (1952) e Arroyo (1968), o que considero

[...] um corpus básico do discurso sobre LIJ, em decorrência de suas características de sistematização e de sua contribuição para a fundação e consolidação de um tema de pesquisa/campo de conhecimento. Ape-

4 Detalhado e competente estudo sobre a produção de Lourenço Filho de e sobre literatura infantil se encontra em Bertoletti (2012), resultante de tese de doutorado que orientei. 
sar de suas diferentes formações e pontos de vista teóricos, os autores dos textos mencionados apresentam pontos em comum, indicativos de permanência e rupturas, no que se refere à definição e conceituação da LIJ e a sua função e utilização na escola (MORTATTI, 2008a, p. 7).

O conhecimento então produzido, como resposta para os problemas formulados nas últimas décadas do século XX, atribuiu novos sentidos à literatura infantil e ao ensino da literatura. Fundou-se, assim, uma nova tradição até hoje atuante, incorporada principalmente no discurso acadêmico, na produção editorial e, na medida da conveniência e das possibilidades de sínteses ecléticas, no discurso pedagógico oficial. ${ }^{5}$

Talvez essas questões tenham sido incorporadas, também, na prática pedagógica de professores dos anos finais do ensino fundamental e do ensino médio, como decorrência tanto da veiculação desses temas nos cursos de licenciatura em Letras quanto de sua assimilação em livros didáticos e em documentos oficiais. Por certo mais difusa e imperceptivelmente, foram incorporadas à prática pedagógica dos professores da educação infantil e dos anos iniciais do ensino fundamental. Na grade curricular do curso de Pedagogia, responsável pela formação desses professores, literatura infantil ou não consta como disciplina obrigatória ${ }^{6}$, ou consta de forma secundária, como disciplina optativa, ou matéria agregada a disciplinas referentes à alfabetização e ao ensino de língua portuguesa. Inclusive porque esse "não lugar" é aparentemente paradoxal quando se consideram: a abundância da produção brasileira atual de livros de literatura infantil e de sua circulação na escola, por meio de programas governamentais; e a ênfase nas habilidades e competências em leitura definidas em orientações curriculares e programas de formação contínua de professores.

5 Na década de 1980, inicia-se, também, o que denominei "quarto momento crucial na história da alfabetização no Brasil" (MORTATTI, 2000), o qual está diretamente relacionado com o que discuto neste artigo.

6 A disciplina "literatura infantil" passou a constar dos programas dos cursos de formação de professores no Estado de São Paulo a partir de 1957, tendo sido extinta juntamente com a reformulação do Curso Normal, com a lei 5.692/71. Detalhado e competente estudo sobre o assunto se encontra na tese de doutorado (em andamento) de Fernando Rodrigues de Oliveira, intitulada "História do ensino da literatura infantil nos cursos de formação de professores primários no estado de São Paulo, Brasil (1947-2003)” (Bolsa FAPESP - PDSE-CAPES), a qual estou orientando. 


\section{Literatura: conceito e função}

No âmbito dessa nova tradição, dada a contribuição dos estudos literários para a proposição do ensino da literatura e da literatura infantil e juvenil como temas e objetos de estudo e pesquisa, a discussão central recaiu sobre o conceito de literatura. Embora a tentativa de defini-lo seja sempre uma tarefa difícil, como mostram as vertentes teóricas que, ao longo do século XX, empenharam-se nessa tarefa, algumas aproximações são necessárias para estabelecer as bases da problematização proposta neste artigo.

O sentido que atribuo a "ensino da literatura" está em consonância com o ponto de vista segundo o qual, assim como a educação (escolar), a literatura é um direito humano e desempenha papel fundamental na formação humana.

O ensino da literatura é um momento didático-pedagógico do ensino escolar formal, intencional e organizado, que, por sua vez, integra o processo de formação (integral), com a finalidade de contribuir para o processo de emancipação humana. Assim, na expressão "ensino da literatura", tem-se, simultaneamente, a indicação de objeto de ensino escolar e de um momento específico de ensino e aprendizagem, que integra o processo educativo e que se refere ao lugar e à contribuição da literatura para a educação, por meio do ensino.

As ambiguidades, porém, permanecem se não se enfrentam problemas antigos e muitas vezes "estranhos" às ciências da educação. Nessa área, tal pode ser a ênfase nos substantivos "educação" ou "ensino", cujos significados têm sido bastante explorados e discutidos, que o sentido de "literatura" pode passar despercebido ou secundarizado, como se fosse autoexplicativo.

Tratando do direito à literatura, entendida em sentido amplo, o crítico literário Antonio Candido retoma um clássico texto seu, publicado em 1972, em que discute a importante função da literatura no processo de formação humana, com seus aspectos paradoxais "[...] na medida em que os educadores ao mesmo tempo preconizam e temem o efeito dos textos literários" (CANDIDO, 1995a, p. 176):

De fato (dizia eu [no texto de 1972]), há “conflito entre a idéia convencional de uma literatura que eleva e edifica (segundo os padrões oficiais) e a sua poderosa força indiscriminada de iniciação na vida, com uma variada complexidade nem sempre desejada pelos educadores. Ela não corrompe nem edifica, portanto; mas trazendo livremente em si o que chamamos o bem e o que chamamos o mal, humaniza em sentido profundo, porque faz viver. 
$[\ldots]$

A função da literatura está ligada à complexidade da sua natureza, que explica inclusive o papel contraditório, mas humanizador (talvez humanizador porque contraditório) (CANDIDO, 1995a, p. 176).

Buscando contemplar a fluidez do termo, com objetivos relacionados às necessidades de desenvolvimento de trabalhos acadêmicos, desde os primeiros estudos, na década de 1980, tenho optado por uma definição aproximativa de literatura, como: conjunto de textos, enfeixados sob essa denominação, em decorrência de determinadas

[...] condições de emergência [...] produção, edição, difusão, instituições escolares e universitárias, as condições de aprendizagem da língua e da leitura, diferentes instâncias legislativas nesse domínio como as academias, os prêmios literários, as revistas, a definição de "domínio cultural" e de "corpus literário", e a imagem implícita e pressuposta de leitor e de leitura, sem hierarquização entre esses elementos (MAGNANI, 1989, p. 6).

Em que pese sua abrangência, essa definição não tem sentido relativista e não desconsidera a necessidade de enfatizar a fruição estética e de discutir juízos de valor estético na vida e na escola.

Enquanto obra de linguagem eminentemente qualitativa, que exalta a diferença e a interação do que é diverso, e dado seu caráter de gratuidade e permanência no tempo, o texto literário demanda e propicia um trabalho específico de leitura, ao mesmo tempo como fruição estética, que não se deixa controlar, instrumentalizar, etapizar ou seriar, e como busca de conhecimento que não se restringe à organização, classificação e computação de dados e informações, mas que se apresenta como multiplicidade, contrapondo-se ao consumo e destruição dos objetos culturais e instaurando outras relações dos sujeitos entre si e com seu passado, presente e futuro, com a cultura e a língua, com o mundo público e o privado. Nesse corpus, destacam-se os "clássicos", aqueles livros que, segundo Calvino (1993), "exercem uma influência particular quando se impõem como inesquecíveis" (p. 10); e "quanto mais pensamos conhecer por ouvir dizer, quando são lidos de fato mais se revelam novos, inesperados, inéditos" (p. 12) porque propiciam a grata surpresa da descoberta de 
algo não necessariamente desconhecido, senão "que sempre soubéramos (ou acreditávamos saber) mas desconhecíamos que [eles o disseram] primeiro (ou de algum modo se liga a [eles] de maneira particular)." (MAGNANI, 1995, p. 12).

\section{Ensino de literatura, leitura do texto literário e formação de leitores}

Pode-se, então, entender que, especialmente no caso brasileiro, o ensino da literatura na escola se concretiza por meio da leitura do texto literário, com o objetivo de formar leitores da literatura. E, se possível, também por meio da escrita de textos literários, o que não significa, porém, que a escola tenha como objetivo e função formar escritores (de literatura). ${ }^{7}$

Desse ponto de vista, podem-se propor três sentidos ${ }^{8}$, complementares entre si, para o processo de educação (escolar) literária propiciado pelo ensino da literatura:

a) educação $d a$ literatura, ou seja, a literatura (em si e por si) educa/ensina:

[...] os (bons) textos literários encantam e ensinam (obviamente, se lidos, ou pelo menos ouvidos), porque fazem diferença em nossas vidas, constituem experiências profundamente humanas [...], porque nos ajudam a formular perguntas para nossa vida, estimulam nossa sabedoria, nossa busca de conhecimento de nós mesmos e do mundo. Nesse sentido, encantam e ensinam, porque, lendo-os, aprendemos algo sobre nossa vida, ao mesmo tempo em que aprendemos sobre a importância da literatura na formação do ser humano [...] Esses textos têm, portanto, uma função formativa específica (MORTATTI, 2008b, p. 27).

b) educação pela literatura, ou seja, a literatura é meio (não é instrumento) para a educação humana.

Diferentemente do sentido pragmático e utilitário que foi objeto de crítica na década de 1980, o sentido de "ensino pela literatura" aqui proposto funda-

7 Recordo casos de pessoas que, não por causa da escola, mas apesar dela ou de fora dela, tornaram-se leitores e escritores. Como exemplo, veja-se o caso de Alzira Silvério, que analiso em Mortatti (2013).

8 Para a formulação desses três sentidos, inspiro-me, por meio de analogia imperfeita, em Geraldi (1993), quando esse linguista se refere às atividades de, com e sobre a linguagem. 
menta-se na compreensão do caráter mediador do texto literário, entendendo-se "mediação" como relação instauradora e "[...] constitutiva, ação que modifica, que transforma". (ORLANDI, 1987, p. 25); e

c) educação para a literatura, ou seja, a literatura é, ela mesma, objeto de ensino, visando à educação literária:

[...] o termo "objeto" refere-se não a um dado puro ou a um produto acabado e inerte a ser dissecado pela leitura, mas ao constante processo de produção de texto [literário] como objeto de fruição e conhecimento, o que ocorre nas relações entre autor e leitor, e, em particular, como objeto também de estudo nas relações escolares de ensino-aprendizagem [...] da literatura; [...]. O que se deve considerar, portanto, é o trabalho de linguagem que se produz, $[. .$.$] mediante o uso da palavra escrita, a qual$ associa o traço visível à coisa invisível, à coisa ausente, à coisa desejada ou temida, como uma frágil passarela sobre o abismo (CALVINO, 1990, p. 90, apud MAGNANI, 1995, p. 38).

Desse ponto de vista, ainda, ensinar literatura é formar leitores do (bom) texto literário e formar o gosto estético desses leitores, entendendo-se "gosto" como a "principal atividade cultural, entre as faculdades políticas dos homens" (ARENDT, 1979, p. 277):

[...] a faculdade de discriminar, discernir e tomar decisões entre diferentes qualidades e valores social e historicamente produzidos, como fenômenos do mundo público da cultura, onde se cruzam arte e política; e, especialmente, qualidades e valores relativos aos menos úteis e mundanos objetos culturais: as obras de arte e, em particular, as obras literárias (MAGNANI, 1995, p. 35).

Não é possível, porém, discriminar qualidades e valores, quando não se conhecem opções, quando o "gosto" se confunde com o hábito e a repetição do mesmo e conhecido.

Se o gosto se aprende, pode ser ensinado. A aprendizagem comporta uma face não espontânea e pressupõe intervenção intencional e construtiva. Assim, o professor tem um importante papel a desempenhar no desenvol- 
vimento de seus alunos/leitores. [...] seu principal papel é o de articular princípios e práticas. E isso significa que tudo que vem sendo e vai ser dito sobre a leitura da literatura precisa fazer parte da vida do professor. [...]

A formação e a transformação do gosto não se dão num passe de mágica. Com a escola - em que pesem as restrições de sua incompetência competente - concorrem todos os outros estímulos e desestímulos com os quais convivem professores e alunos nas horas restantes do dia.

[...] Cabe ao professor romper com o estabelecido, propor a busca e apontar o avanço. Para isso é preciso problematizar o conhecido, transformando-o num desafio que propicie o movimento (MAGNANI, 1992, p. 105).

E, se é na escola que, para a maioria dos brasileiros, ocorre o aprendizado da leitura, é também nesse espaço institucional que:

[...] tendem a ser moldados indeléveis "comportamentos leitores" extra-escolares e pós-escolares, resultantes da promoção e rotinização de [...] práticas burocratizadas e banalizadas de leitura do texto [literário]. Por isso é nesse espaço institucional que mais se podem (de)formar leitores, adaptando-os àquelas necessidades pragmáticas da leitura e achatando seus horizontes de expectativas, por meio da repetição cotidiana de incessantes exercícios de "mesmidade", por exemplo, de modos de ler apenas "camadas mais aparentes" de um escrito, de tipos e gêneros textuais considerados “do cotidiano" (MORTATTI, 2007b, p. 10).

E, por esses motivos, é também na escola que se desrespeita o direito à literatura, quando os professores e demais educadores escolares, embora muito bem intencionados ${ }^{9}$ :

9 Pode-se recordar aqui a crítica de Vigotski, em livro publicado originalmente em 1926, ao "ideal primitivo do pedagogo-babá" e às implicações para a educação estética: "Está claro para qualquer um que quanto mais forte é o incômodo que dá o primeiro impulso ao movimento da alma tanto mais forte é o próprio movimento, que a educação e a criação são sempre trágicas porque partem do 'incômodo' e do mal-estar, da desarmonia. [...] É justamente por ser a infância a época da educação que ela é a época mais trágica, época da desarmonia e da discrepância do organismo com o meio. A música da educação surge de uma dissonância que ela procura resolver. [...] Toda aquela pedagogia que adocicava a 'época dourada da infância serena' e o processo educativo com água de rosas está fora de nosso caminho. Sabemos que o maior motor da educação é o lado trágico da infância, como a fome e a sede são os inspiradores da luta pela sobrevivência. Por isso a edu- 
[...] fazem da leitura um exercício escolar e escolarizado; supondo se adequarem ao "gosto", aos interesses e à realidade dos leitores em formação, impedem-nos de avançar e conhecer aquilo que nem sabem existir; quando não se consideram sujeitos, também eles, desse contínuo processo de formação como leitores de configurações textuais (MORTATTI, 2007b, p. 10).

O "direito à literatura" se refere, portanto, ao direito à leitura literária de bons textos literários, como "[...] lugar de resistência à desumanizante (des) razão, à redução do ler e escrever a finalidades pragmáticas impostas por uma sociedade semi-letrada como a nossa, de cujo cotidiano a literatura não faz parte", lamentavelmente (MORTATTI, 2007a, p. 6). Pois,

[...] tanto quanto a comer, morar, estudar e ser amadas, todas as crianças brasileiras têm direito a aprender a ler e produzir textos, como um inalienável e substantivo direito à inclusão no mundo público da cultura letrada e em justo respeito a sua condição de ser humano em formação. Mas isso ainda é pouco: todas as crianças (e jovens e adultos e idosos) e também todos os professores deste país têm direito a muito mais; têm direito aos tesouros escondidos, também e sobretudo, nos bons textos literários que lhes vêm sendo proibidos, justamente em nome de um suposto "respeito" a suas precárias condições culturais e sociais, justamente em nome de sua "salvação"; e têm direito já à conquista e à fruição desse direito, porque muitas de nossas crianças poderão ter morrido de "bala ou vício", bem antes que [sejam consideradas] prontas, maduras e, finalmente, autorizadas a ler [bons textos literários] (MORTATTI, 2010, p. 148).

\section{Ensino da literatura e leitura de configurações textuais}

Se é possível o ensino da literatura na escola, o que cabe ao professor? Ler e ensinar seus alunos a ler bons textos literários. Assim, tão simplesmente enunciada, a resposta pode parecer um truísmo. É antes um fecundo problema teórico-metodológico, que envolve a necessidade de abordagem interdisciplinar

cação deve ser orientada no sentido de não turvar e nem escamotear os traços cruéis do verdadeiro desconforto da infância mas fazer a criança chocar-se da forma mais brusca e frequente com esse desconforto e levá-la a vencê-lo (VIGOTSKI, 2004, p. 461). 
da leitura literária do texto literário na escola. Esse problema, não somente continua sendo o ponto central das dificuldades relativas ao ensino da literatura e da educação literária, como também se ampliou, neste século, como decorrência da "revolução digital", que impõe ao texto (literário) novas configurações e, a autor e leitor, novos modos de participar da construção e usufruto da grande "biblioteca sem muros" (CHARTIER, 1998).

Na década de 1980, em que fui movida por urgências relativas tanto à atividade docente quanto à de pesquisadora em formação, os ousados objetivos que formulei para a pesquisa de mestrado demandaram também escolher, dentre certas contribuições teórico-metodológicas disponíveis e legitimadas pelo clima cultural-acadêmico da época, aquelas que ofereciam possibilidades de tratamento mais coerente e exploração mais adequada das questões que pretendia abordar, sem desconsiderar a especificidade dos textos do gênero nem sua relação com a literatura e com a escola.

Opondo-me às análises textuais realizadas habitualmente na escola e na universidade, defendia o seguinte ponto de vista:

[...] o que o caracteriza como literário não é apenas o assunto ou seu conteúdo. E, se queremos oferecer condições de avanço com a literatura, é necessário levar em conta que se lida com o todo de um texto: o que, como, quando, quem, onde, por que, para que, para quem se diz. É nessa unidade que o leitor se movimenta quando lê; é esse conjunto de relações que forma e não a moral da história ou as lições de comportamento, ou os conteúdos revolucionários... (MAGNANI, 1992, p. 104).

E, com base no conhecimento sobre o assunto, então disponível ou em construção, busquei formular proposta de abordagem e método de análise que contemplasse a complexidade e a singularidade do texto de literatura infantil e juvenil. Naquele momento, defini, de maneira mais sistemática, a necessidade de a análise contemplar os aspectos "intratextuais", "extratextuais" e "intertextuais" (MAGNANI, 1989), uma vez que:

[...] num campo ainda incipiente e com tantos problemas a serem enfrentados, fazia-se necessário um outro tipo de abordagem da literatura infanto-juvenil, de caráter interdisciplinar e derivado das inexoráveis relações entre a produção do gênero e a situação de formação (escolar) do leitor previsto, a fim de: contemplar a unidade múltipla determinan- 
temente constitutiva do gênero, simultaneamente literário e didático; compreender e mostrar seus aspectos específicos, mediante análise crítica de textos; e explicar e buscar superar o gosto (estético) dos leitores crianças e jovens, o qual justificava e realimentava a produção em série e a reiterada utilização nas escolas de textos de pouca qualidade estética, responsáveis pela formação de leitores consumidores da trivialidade literária, cultural, histórica e política (MAGNANI, 2001, p. XV).

A partir daquelas preocupações iniciais, formulei o conceito de "configuração textual" 10 , por meio do qual busco nomear o conjunto dos aspectos que conferem a um escrito sua singularidade como texto (ponto de partida e de chegada da leitura e da escrita) e sua unidade de sentido. Essa formulação foi ampliada em Magnani (1993) ${ }^{11}$ e estabelecida de forma mais acabada em Mortatti (2000). Assim, com o conceito de configuração textual passei a nomear o conjunto de aspectos que se referem às:

[...] opções temático-conteudísticas (o quê?) e estruturais-formais (como?) projetadas por determinado autor (quem?), que se apresenta como sujeito de um discurso produzido de determinado ponto de vista e lugar social (de onde?) e momento histórico (quando?), movido por certas necessidades (por quê?) e propósitos (para quê?) e visando a determinado efeito em determinado tipo de leitor previsto (para quem?); assim como a circulação, utilização e repercussão logradas pelo projeto do autor ao longo da história (de leitura) do texto (MORTATTI, 2000, p. 31).

Com base nesse conceito, formulei o método de análise da configuração textual, que "[...] possibilita enfrentarem-se vários dos problemas envolvidos na atividade crítica, especialmente a tendência à redução do processo analítico a aspectos isolados da configuração textual." (MAGNANI, 2001, p. XVII; grifos da autora).

10 Bakhtin (1981), Starobinski (1988) e Candido (1995b) são alguns dos autores em que me inspirei. Para uma expansão do conceito de configuração textual e suas possibilidades de aplicação na leitura de textos (não somente os literários) nas aulas de língua portuguesa e literatura, em todos os níveis de ensino, ver especialmente: Magnani (1993) e Mortatti (2000).

11 Trata-se da publicação em livro da tese de doutorado da autora, defendida em 1991, junto ao PPGE-FE/UNICAMP. 
Assim compreendida, a atividade de leitura demanda um movimento crescente que implica deslocamentos do lugar do leitor necessariamente envolvido para o leitor necessariamente crítico (MORTATTI, 2001). Esse deslocamento exige do leitor a busca de distanciamento, que parte da pergunta "por que gostei (ou não)?" e, por meio da análise da configuração textual, a reflexão sobre o texto e sobre a relação de envolvimento provocada nele (leitor). Propiciando condições para desestabilização do "funcionamento conforme" dos textos e da leitura, a utilização desse método contribui para o enfrentamento da questão do valor estético e se opõe ativamente à perpetuação de uma "cultura da idiotia" (MORTATTI, 2007b).

\section{Ensino da literatura, letramento literário e educação literária}

Talvez por causa desse lugar ambíguo da literatura na escola - em especial no ensino fundamental, onde se fazem sentir mais agudamente os efeitos da crise endêmica da educação brasileira - "letramento literário" e "educação literária" sejam temas emergentes na pauta atual de discussões e propostas, talvez com o objetivo de substituir, por equivalência ou por ampliação de sentido, a expressão "ensino da literatura", incluindo a literatura infantil e juvenil. Ou talvez porque o conhecimento acumulado sobre o assunto, uma vez incorporado como tradição, esteja a demandar não revisão, mas ampliação de suas potencialidades explicativas e aplicativas, em função do novo contexto social, cultural e educacional do país neste século. Ou talvez, ainda, porque se considere que "ensino da literatura" tenha-se mostrado insuficiente para designar a complexidade dos problemas atuais, relativos tanto aos conceitos de literatura e de ensino, quanto à função e à circulação do texto literário na escola brasileira, em tempos de produção e difusão de textos em outros suportes e meios. Ou, talvez, ainda, porque simplesmente novos nomes para antigos problemas sejam necessários para desautomatizar pensamento e ação.

Embora o objetivo não seja discutir questões terminológicas e conceituais, por necessidade de clareza, apresento exemplos dos principais aspectos das discussões atuais sobre educação literária e letramento literário em circulação em textos acadêmico-científicos de pesquisadores galegos, portugueses e brasileiros.

Enfocando a formação do mediador para realizar a "animação leitora" dirigida à "educação multicultural", a pesquisadora galega Blanca-Anna Roig Rechou (2012, p. 362) apresenta "o que se entende por "educação literária"”: 
[...] una metodología con la que se pretende dotar al mediador de un conjunto de saberes culturales, literarios y sociales proporcionados por las enciclopedias y los intertextos individuales, que le permita capacitar a los lectores para descubrir en las obras literarias, modelos, pautas, convencionalismos, símbolos, mitos, acontecimientos históricos... reacción individual ante la lectura.

Com sentido similar, em Marcos, Silva e González (2013), com base nas pesquisas sobre o tema realizadas em Portugal e na Galícia, enfatiza-se a importância do estudo atento da literatura infantil e juvenil como imprescindível para a educação literária, a ser promovida tanto por educadores e professores quanto por pais e outros profissionais.

No documento "Metas curriculares de Português - Ensino Básico", do Ministério da Educação e Ciência de Portugal, educação literária ganha destaque como um dos "domínios de referência" no currículo escolar. Não se apresenta uma definição, mas podem-se inferir aspectos de seu significado, por meio da função atribuída a esse domínio, que:

[...] congregou vários descritores que antes estavam dispersos por diferentes domínios. Tal corresponde a uma opção de política da língua e de política de ensino. Por um lado, a Literatura, como repositório de todas as possibilidades históricas da língua, veicula tradições e valores e é, como tal, parte integrante do património nacional; por outro, a Educação Literária contribui para a formação completa do indivíduo e do cidadão (PORTUGAL, 2012, p. 5).

Em textos de pesquisadores brasileiros, a expressão "educação literária" remete e por vezes equivale a "letramento literário", o qual, em extensão ao sentido do termo "letramento" (SOARES, 1998), vem sendo entendido como "[...] o processo de apropriação da literatura enquanto construção literária de sentidos." (PAULINO; COSSON, 2009, p. 67). Trata-se de "letramento singular" porque "[...] tem uma relação diferenciada com a escrita" (SOUZA; COSSON, 2013, p. 102).

Para estes autores,

[...] o objetivo maior do letramento literário escolar ou da educação literária na escola é nos formar como leitores, "não como qualquer leitor ou um 
leitor qualquer", mas um leitor capaz de se inserir em uma comunidade, manipular seus instrumentos culturais e construir com eles um sentido para si e para o mundo em que vive (SOUZA; COSSON, 2013, p. 106).

E, com base nessa "nova abordagem", Junqueira de Souza e Guizelim Simões $(2011$, p. 1) apresentam as possibilidades do ensino das estratégias de leitura a partir de textos literários, como alternativa metodológica para o início da educação literária.

Como se pode constatar, esses significados de "letramento literário" e "educação literária" contemplam muitas das discussões e propostas para o ensino da literatura que abordei nas páginas anteriores deste artigo. E, possivelmente, não tivesse sido necessária a emergência de novos temas e designações se tivessem se concretizado avanços reais em termos de leitura do texto literário na escola brasileira e em outras instâncias da vida social e cultural do país. ${ }^{12} \mathrm{Ou}$, possivelmente, as expressões "letramento literário" e "educação literária" venham a sintetizar tensões e anseios antigos, para retomá-los, ampliando pontos de vista e relações com outros campos de pesquisa, assim como outras expectativas de concretizá-los no novo contexto sociocultural do século XXI.

\section{Considerações finais}

Embora possa ser questionada sob a acusação de parcialidade, a história do ensino da literatura sintetizada neste artigo indica a pertinência de questões de fundo: o que significa ensinar literatura na escola pública brasileira no século XXI? O que um professor precisa aprender/saber para ensinar literatura, ou para promover o "letramento literário" ou a "educação literária"?

Considerando que inexiste literatura ou equivalente como matéria/disciplina curricular nos anos iniciais de ensino fundamental e, em decorrência, também inexiste disciplina equivalente no curso de licenciatura em Pedagogia; considerando também que gerações de professorandos e professores não se formaram (na escola ou fora dela) como leitores da (boa) literatura, pouco ou nada adianta que aprendam metodologias e estratégias para promover o letramento literário ou a educação literária. Contrariamente a declaradas boas intenções, professores

12 Em Mortatti (2007c), apresento questionamento semelhante sobre a introdução, na década de 1990, no Brasil, do termo "letramento" em relação direta com o termo "alfabetização". 
não leitores podem contribuir para a concretização do perigo para o qual, em 1926, advertia Vigotski: “[...] o melhor meio de infundir ódio a algum escrito e levar a que ele não seja lido é introduzi-lo no currículo escolar." (2004, p. 328).

Aos professores não leitores falta o essencial: a vivência da fruição estética. Sem isso, sequer podem saber a importância de lutar pela conquista, para si, do direito à literatura, antes de, com palavras vazias, tentar convencer seus alunos sobre a "importância da literatura".

Ilustra essa pessimista reflexão um fato ocorrido recentemente em uma aula da disciplina "Conteúdo, metodologia e prática de ensino: língua portuguesa e literatura infantil", que ministro em curso de Pedagogia. Coerentemente com o ponto de vista que apresentei neste artigo, no início de todas as aulas, leio um bom texto literário (completo), "simplesmente" com o objetivo de propiciar vivências estéticas. Eu lia o conto "Felicidade clandestina", de Clarice Lispector, e todos estavam atentos e envolvidos com a história, até que, próximo ao clímax, uma aluna cutucou a colega ao lado e ambas soltaram risinhos ruidosos o suficiente para indicarem sua desatenção e desinteresse. Interrompi a leitura e explicitei minha frustração com a falta de sensibilidade que demonstraram em relação a uma obra assim bela. Em "legítima defesa", a aluna responsável pelo incidente se justificou: “eu só estava dizendo para ela que já conheço esse conto; a professora deu para a gente ler na escola"...

É possível, porém, nutrir ainda certa esperança de que professores e alunos consigam, apesar da escola, compreender sua condição de sujeitos sócio-históricos e o sentido profundamente humano e humanizador da literatura, direito conquistado quando se aprende, por meio da vivência e fruição estéticas, que "[...] há coisas que só a literatura com seus meios específicos nos pode dar." (CALVINO, 1990, p.11) e que "Tudo que é belo é uma alegria para sempre/ O seu encanto cresce; não cairá no nada" (KEATS, 1987).

\section{REFERÊNCIAS}

ARENDT, H. A crise na educação. In: Entre o passado e o futuro. Trad. Mauro W. B. Almeida. 2. ed. São Paulo: Perspectiva, 1979. p. 221-247.

ARROYO, L. Literatura infantil brasileira: ensaio de preliminares para sua história e suas fontes. São Paulo: Melhoramentos, 1968.

AZEVEDO, Fernando. A literatura infantil numa perspectiva sociológica. Sociologia (Escola de Sociologia e Política), vol. XIV, n. 1, mar. 1952. 
BAKTHIN, M. Marxismo e filosofia da linguagem. Trad. M. Lahud e Y. F. Veira. 2. ed. São Paulo: HUCITEC, 1981.

BERTOLETTI, E. N. M. Lourenço Filho e a literatura infantil e juvenil. São Paulo: Editora UNESP, 2012.

CALVINO, I. Seis propostas para o próximo milênio. Trad. I. Barroso. São Paulo: Companhia das Letras, 1990. 1993. . Por que ler os clássicos. Trad. N. Moulin. São Paulo: Companhia das Letras,

CANDIDO, A. O direito à literatura. In: . Vários escritos. 4. ed. reorg. São Paulo: Duas Cidades, 1995a. p. 169-192. . O discurso e a cidade. São Paulo: Duas Cidades, 1995b.

CHARTIER, R. A aventura do livro: do leitor ao navegador. Trad. R. C. C. Moraes. São Paulo: Editora UNESP; Imprensa Oficial, 1998.

COELHO, N. N. A literatura infantil: história, teoria, análise. 3. ed. São Paulo: Quiron, 1984.

GERALDI, J. W. Portos de passagem: linguagem, interação e ensino. São Paulo: Martins Fontes, 1993.

GUIZELIM SIMÕES, C. G.; JUNQUEIRA DE SOUZA, R. Estratégias de leitura: uma alternativa para o início da educação literária. Álabe 4, diciembre 2011. Disponível em: $<$ http://www.ual.es/alabe]>; <http://revistaalabe.com/index/alabe/article/view/87>. Acesso em: 25/10/2013.

KEATS, J. Endimião. In: . Poemas de John Keats. Trad. P. E. S. Ramos. 2. ed. revista. São Paulo: Martins Fontes, 1987. p. 77-79.

LAJOLO, M. Usos e abusos da literatura na escola (Bilac e a literatura escolar na República Velha). São Paulo: Universidade de São Paulo, Tese (Doutorado), 1979. (mimeo.).

. Texto não é pretexto. In: ZILBERMAN, R. (Org.). A leitura em crise na escola: as alternativas do professor. Porto Alegre: Mercado Aberto, 1982. p. 51-62.

LAJOLO, M.; ZILBERMAN, R. Literatura infantil brasileira: história \& histórias. São Paulo: Ática, 1984.

LEITE, L. C. M. Invasão da catedral: literatura e ensino em debate. Porto Alegre: Mercado Aberto, 1983.

LOURENÇO FILHO, M. B. Como aperfeiçoar a literatura infantil. Revista Brasileira (RJ), v. 3, n. 7, p. 146-169, set. 1943.

MAGNANI, M. R. M. Literatura e educação em Cecília Meireles. 8 fls. Trabalho final da disciplina "Evolução da educação brasileira" - professor Casemiro dos Reis Filho Mestrado em Educação - FE-UNICAMP. Campinas, 1980 (datilog.). 
. A leitura escolarizada. Leitura. Teoria \& Prática, n. 11, p. 15-21, 1988.

Fontes, 1989.

. Leitura, literatura e escola: sobre a formação do gosto. São Paulo: Martins .Em sobressaltos: formação de professora. Campinas: Editora da Unicamp, 1993.

. Leitura e formação do gosto (por uma pedagogia do desafio do desejo). Idéias

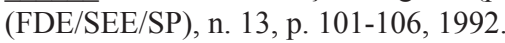

. Sobre ensino da leitura. Leitura. Teoria \& Prática, n. 25, p. 29-41, 1995.

. Prefácio à $2^{\mathrm{a}}$. edição. In: Leitura, literatura e escola: sobre a formação do gosto. São Paulo: Martins Fontes, 2001. p. XIII-XIX.

MARCOS, M. M.; SILVA, C. T. S; GONZÁLEZ, I. M. (Coord.). Literatura para a infância e a juventude e educação literária. Lisboa: Deriva Editores, 2013.

MEIRELLES, C. Problemas da literatura infantil. Belo Horizonte: Imprensa Oficial, 1951.

MORTATTI, M. R. L. Os sentidos da alfabetização: São Paulo -1876/1994. Brasília/ DF: MEC/INEP/CONPED; São Paulo: Editora UNESP, 2000.

. Leitura crítica da literatura infantil. Itinerários - Revista de Literatura, Araraquara, n. 17, p. 179-187, 2001. Disponível em: <http://seer.fclar.unesp.br/itinerarios/ article/view/ 3458>. Acesso em: 25/10/2013.

. Literatura (a boa): mantenha sempre ao alcance das crianças. Criar - Revista de Educação Infantil, n. 18, p. 8-13, nov./dez. 2007a.

. Armadilhas discursivas da leitura: contra a ditadura da idiotia. In: CONGRESSO DE LEITURA DO BRASIL, 16., 2007, Campinas. Anais... Campinas: ALB, 2007b. p. 1-14. Disponível em: <http://alb.com.br/arquivo-morto/edicoes_anteriores/anais16/ conferencias/07 mariadorosariomortatti.pdf $>$. Acesso em: 25/10/2013.

. Letrar é preciso, alfabetizar não basta ... mais? In: SCHOLZE, L.; ROSLING, T. M. K. (Org.). Teorias e práticas de letramento. Brasília: INEP; Passo Fundo: Editora UFPF, 2007c, p. 155-168. Disponível em: <http://www.publicacoes.inep.gov.br/arquivos/ \%7B71A1445D-FD55-462B-AC0F-F6E106D3DD98\%7D_MIOLO_Teorias_Praticas Letramento.pdf $>$. Acesso em: 25/10/2013.

. Literatura infantil e/ou juvenil: a "prima pobre" da pesquisa em Letras?. Guavira Letras, v. 6, p. 43-52, 2008a. Disponível em: < http://www.pgletras.ufms.br/revistaguavira/ downloads/revguavira006.pdf $>$. Acesso em: 25/10/2013.

. Literatura e ensino: notas ¿quixotescas? da fronteira. Leitura. Teoria \& Prática,

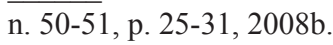

. O direito ao texto. In: BARCELOS, V.; ANTUNES, H. S. Alfabetização, Letramento e Leitura: territórios formativos. Santa Cruz do Sul-RS: EdUNISC, 2010, p. 137-148. 
. O livro de Alzira. Educação, UFSM, v. 38, n. 1, jan./abr. 2013. Disponí$\overline{\text { vel em: }}<$ http://cascavel.ufsm.br/revistas/ojs-2.2.2/index.php/reveducacao/article/ view/5864/4530>. Acesso em: 25/10/2013.

ORLANDI, E. P. A linguagem e seu funcionamento: as formas de discurso. 2. ed. Campinas: Pontes, 1987.

PAULINO, G.; COSSON, R. Letramento literário: para viver a literatura dentro e fora da escola. In: ZILBERMAN, R.; RÖSING, T. (Orgs.). Escola e leitura: velha crise; novas alternativas. São Paulo: Global, 2009.

PERROTTI, E. O texto sedutor na literatura infantil. São Paulo: Ícone, 1986.

PORTUGAL. Ministério da Educação e Ciência. Metas curriculares de Português: Ensino Básico $-1 .^{\circ}, 2 .^{\circ}$ e $3 .^{\circ}$ ciclos (Propostas pela Equipa de Português: H. C. Buescu, J. Morais, M. R. Rocha, V. F. Magalhães). 2012. Disponível em: <http://www.portugal. gov.pt/media/675639/portugu_s.pdf>. Acesso em: 25/10/2013.

RECHOU, B-A. R. Educación literaria. Literatura infantil y juvenil. Una propuesta multicultural. Educação, Porto Alegre, v. 35, n. 3, p. 362-370, set./dez. 2012. Disponível em: <http://revistaseletronicas.pucrs.br/ojs/index.php/faced/article/view/11769/8393>. Acesso em: 25/10/2013.

ROSEMBERG, F. Literatura infantil e ideologia. São Paulo: Global, 1985.

SOARES, M. Letramento: um tema em três gêneros. Belo Horizonte: Autêntica, 1998.

SOUZA, R. J.; COSSON, R. Letramento literário: uma proposta para a sala de aula. São Paulo: UNESP/UNIVESP. Disponível em: < http://www.acervodigital.unesp.br/bitstream/ 123456789/40143/1/01d16t08.pdf>. Acesso em: 25/10/2013.

STAROBINSKI, J. A literatura: o texto e seu intérprete. In: LE GOFF, J.; NORA, P. (Dir.). História: novas abordagens. Trad. H. Mesquita. Rio de Janeiro: F. Alves, 1988. p. 132-143.

VIGOTSKI, L. S. Psicologia pedagógica. Trad. do russo e introdução de P. Bezerra. 2. ed. São Paulo: Martins Fontes, 2004. p. 323-363. (1ª . edição do original em russo: 1926).

ZILBERMAN, R. (Org.). A leitura em crise na escola: as alternativas do professor. Porto Alegre: Mercado Aberto, 1982.

. Literatura infantil na escola. São Paulo: Global, 1981.

ZILBERMAN, R.; MAGALHÃES, L. Cademartori. Literatura infantil: autoritarismo e emancipação. São Paulo: Ática, 1982.

Texto recebido em 28 de abril de 2014. Texto aprovado em 05 de maio de 2014. 
